\title{
EDUCACIÓN SUPERIOR Y MUNDO DEL TRABAJO: HORIZONTES DE INDAGACIÓN
}

El propósito de este ensayo es reflexionar sobre las relaciones contemporáneas entre la educación superior (ES) y el mundo del trabajo $^{2}$. El hilo conductor de la argumentación se despliega a lo largo de las preguntas que habitualmente se plantean a las instituciones de educación terciaria en términos de su relación con el mercado laboral. Su objetivo, sin embargo, es ir más allá de estas preguntas, interrogando su validez y pertinencia a la luz de las nuevas condiciones del trabajo en el capitalismo tardío y de las características propias de organización y funcionamiento de la educación superior.

Partimos de un hecho esencial, cual es que la enseñanza superior experimenta hoy una renovada preeminencia en la estimación de los estudiantes y los gobiernos, como señala el reciente estudio de revisión de la educación terciaria en el mundo, producido por la Organización para la Cooperación y el Desarrollo Económico (OECD, 2008). Precisamente por esto surgen también nuevas interrogantes sobre la adecuación del vínculo entre aquella y los mercados laborales. Por ejemplo, dada la fuerte expansión de la matrícula terciaria en el mundo, cabe preguntarse si está produciéndose o no una sobreoferta de graduados en relación con las demandas del mercado de trabajo. ¿Reciben los estudiantes una formación pertinente o existe, por el contrario, un desajuste entre los cursos que ellos eligen -o se les ofrecen- y las necesidades de la economía? ¿Son apropiadas las capacidades y habilidades que los jóvenes adquieren para el desempeño de los roles que exige el mundo ocupacional?

Una serie de estudios abordan este tipo de cuestiones, identifican las respuestas elaboradas en diferentes contextos nacionales y plantean interrogantes adicionales (Alonso, Fernández y Nyssen,

2 El presente artículo fue preparado para el Programa de Investigación en Políticas de Educación Superior (SOC-01) del II Concurso "Anillos de Investigación en Ciencias Sociales" de CONICYT. 
2008; Teichler, 2007, 2007a; Cranmer, 2006). ¿Se hacen cargo las universidades, en sus distintos ciclos formativos, de desarrollar las competencias no tradicionales que las empresas reclaman de los graduados, tales como habilidades sociales, liderazgo, capacidad de trabajo en equipo, gestión del estrés, inteligencia emocional y otras? Más en particular, ¿responden las instituciones educacionales a las expectativas de los empleadores de contar con personal dotado de una específica moral del trabajo -disciplina, responsabilidad, compromiso, productividad, iniciativa propia y disposición al riesgo junto con la capacidad de mantener lealtad con la empresa? ¿Están preparados los docentes universitarios, muchos de ellos académicos de jornada completa con escasa experiencia laboral fuera de la universidad, para transmitir esos principios moral-formativos, además de proporcionar las nuevas competencias que los empleadores esperan de sus trabajadores, técnicos, profesionales y cuadros gerenciales?

Al tenor de la información recogida por estos estudios, las preguntas se suceden. ¿Son compatibles las culturas juveniles posmodernas -con su énfasis en el éxito individual, las satisfacciones inmediatas, la simultaneidad de tareas, la fragmentación de la atención, la sospecha frente a los relatos institucionales y la licuación de los compromisos- con las demandas de los empleadores, cuyo énfasis moral parece aproximarse más al de aquellas culturas puritanas que Weber identificó con el espíritu del capitalismo decimonónico? ¿Están preparados los jóvenes para ingresar a un mercado laboral más y más competitivo e inestable? ¿Cuentan con suficiente información sobre tendencias ocupacionales, expectativas de empleabilidad e ingresos, y suficiente asesoría y consejo vocacionales?

Por otro lado, ¿es realista pensar que los diplomas universitarios son todavía una fuente de estabilidad de las trayectorias laborales y un componente de la identidad de las personas? ¿Transmiten aún una señal distintiva en el mercado de trabajo que permita la selección por méritos y al individuo validar un nivel de ingreso y un estatus en la comunidad?

Sin duda, estas cuestiones adquieren especial relevancia en la misma medida en que los sistemas nacionales de ES continúan 
expandiéndose y las instituciones se diferencian cada vez más en términos de organización y diversidad de programas y estudiantes.

En efecto, la enseñanza superior ha dejado de ser una avenida de pocos cursos que da cabida sólo a una minoría -los herederos del capital cultural, como los llamaron Bourdieu y Passeron (2003) en los años sesenta del pasado siglo- para transformarse progresivamente en un servicio de masas que universaliza el acceso a credenciales en beneficio de personas de diferentes orígenes y edades, y con diversos talentos y necesidades. El peso de la cuna retrocede pero no desaparece. La carrera meritocrática se expande pero no se impone. La formación superior abre sus puertas pero la selección se mantiene ahora en su interior. El ingreso al mercado ocupacional y las trayectorias laborales dependen, sin duda, del nivel formativo de las personas (su capital humano) pero también de sus redes familiares y su capital social (Núñez y Gutiérrez, 2004).

En breve, los sistemas de enseñanza superior se han vuelto enormemente complejos y las instituciones que los componen enfrentan un conjunto diverso y muchas veces contradictorio de demandas provenientes de diversas partes interesadas: estudiantes y sus familias, los propios académicos y administradores universitarios, los empleadores y las empresas, las comunidades locales y regionales, los medios de comunicación, el gobierno y sus agencias, los organismos evaluadores nacionales e internacionales, los financistas, entre otros (Jongbloed, Enders y Salerno, 2008).

Como sea, ahora es posible imaginar, sin incurrir en un lapsus utópico (como todavía parecía ocurrir hace sólo unas pocas décadas), que en el futuro todas las personas, con independencia de su origen, género, trayectoria educacional previa y perspectivas laborales, participarán en algún momento de su vida en algún programa de enseñanza postsecundaria. Podrá ser de forma presencial o a distancia a través de internet; en una institución tradicional o con algún nuevo tipo de proveedor de servicios de educación superior; de manera continua o en diferentes etapas de la vida; con propósitos de beneficio individual (pensando en la tasa de retorno de su inversión) o por motivos diferentes: de consumo cultural, de acción pública, de 
exploración de nuevos horizontes de conocimiento, como parte de un estilo de vida, por ejemplo.

Cada vez más, entonces, las personas elegirán qué estudiar, cuándo y dónde hacerlo, con quiénes, por qué medios y para cuáles fines personales, comunitarios o sociales. Los estudios, en consecuencia, se combinarán de muchas diferentes maneras con el trabajo, al punto que empezará a desaparecer la tajante y tensa brecha que hoy existe entre el mundo de la educación y el mundo del trabajo, la cual ahora solamente se salva cruzando por un puente de incertidumbres y dificultades. Más bien, la incertidumbre y los riesgos se extenderán hacia atrás (a las opciones educacionales) así como gradualmente han ido cubriendo toda la extensión y los momentos del mundo del trabajo (Bauman, 2007). La propia noción de una 'carrera', como fue concebida durante el siglo XX, empieza a desaparecer (Flores y Gray, 2000).

Envueltas en esta marea de masificación, diferenciación, opcionalidad e incertidumbre, también las credenciales expedidas por las instituciones de educación superior -profesionales y técnicas- correrán la suerte de todo lo sólido que se desvanece en el aire. Su poder de señalización en el mercado laboral tenderá a debilitarse, como desde ya ocurre en diversos países del mundo. Su valor de cambio se tornará más inestable aún y su valor simbólico, de generación de estatus e identidad, seguirá debilitándose.

Progresivamente el mercado laboral tenderá a valorar otros elementos más diferentes, como experiencias vividas, aprendizajes en contextos no formalizados, demostraciones de competencias, manejo de sí mismo en distintas situaciones, redes sociales, exposición a retos internacionales y familiaridad en el uso de tecnologías de información e idiomas. A su turno, estos mercados irán adquiriendo también otras modalidades de selección, reclutamiento, segmentación y evaluación de las personas, ya no exclusivamente basadas en el valor atribuido a las credenciales educacionales. En suma, la vieja aspiración burguesa de una carrera abierta a los talentos entra en crisis no sólo por su exacerbación sino, además, porque la propia noción evangélica de talentum empieza a ser reemplazada por conceptos más 
ambiguos y seductores como 'inteligencias múltiples', 'competencias de empleabilidad', 'gestión de conocimientos', 'destrezas blandas', 'liderazgo estratégico' y otras de similar talante.

En estas condiciones cabe preguntarse -en adición a las interrogantes enunciadas antes o, incluso, cuestionando su validezhasta cuándo y de qué manera podrán sustentarse los argumentos que llaman a las universidades a adecuarse y adaptarse a las necesidades de la economía y a las demandas del mercado laboral. ¿Es de suyo evidente, acaso, como suele afirmarse, que ellas deben proceder en tal dirección? ¿Es normal y tiene sentido que ellas transformen sus currículos formativos al ritmo de las exigencias declaradas por los empleadores? ¿Son estas últimas suficientemente claras y distintas como para traducirse en competencias que, a su vez, puedan implementarse curricularmente? En fin, ipuede sin más convertirse el lenguaje de la demanda ocupacional al lenguaje de la oferta formativa? ¿Conocemos el código que permitiría exitosamente hacer esta conversión?

Sin duda, todas estas son preguntas legítimas.

Ellas nos sitúan frente a las nuevas realidades del trabajo en el capitalismo de la modernidad tardía o posmoderno, caracterizadas por el imperativo de la flexibilidad; la continua reinvención discontinua de las instituciones y las reglas del trabajo; la erosión de las tradiciones laborales; la pérdida de las seguridades; la multiplicación de empleos fluidos y cambiantes; la aparición de ocupaciones deslocalizadas y jornadas elásticas; extensas prácticas de subcontratación y externalización de funciones; declinación de las solidaridades del trabajo y los organismos de defensa sindical; precarización de muchos empleos; permanente reingeniería de las empresas y sus modelos de gestión; reemplazo de las cadenas por redes de producción; obsolescencia de los conocimientos ligados a las funciones; evaluación panóptica de los desempeños individuales; internalización e individuación del éxito y el fracaso; desaparición de actividades y su reemplazo por otras en una constante dinámica schumpeteriana de destrucción creativa (Sennett, 1998; Boltanski y Chiapello, 2005). 
¿Cómo podrían adaptarse entonces las instituciones de enseñanza superior $-\mathrm{O}$ adecuarse temporalmente, a lo menos- a esta nueva constelación de circunstancias que caracteriza al mundo del trabajo y al mercado laboral? Más bien, una vez que ellas entran en esta zona de incertidumbres y riesgos, sus resistencias a cambiar y a ordenarse en función de demandas externas también aumentan.

En efecto, las universidades poseen sus propias estructuras y formas de evolución. Tienen tiempos de cambio y conservación que no necesariamente se amoldan con facilidad a esas dinámicas schumpeterianas. Poseen unas formas de división y organización del trabajo que no se prestan expeditamente para la reingeniería ni corren ellas a la misma velocidad de los mudables modelos de gestión empresarial. O, de adoptarlos, corren el peligro de sumarse nada más a una moda que pronto se abandona sin dejar huellas en la administración universitaria (Birnbaum, 2001).

Sus anclas son diferentes también: las disciplinas académicas y sus culturas tribales (Becher, 2001); los procesos de maduración de los jóvenes; la acumulación del conocimiento; la vigencia de la biblioteca; la comunicación oral en la sala de clases; la espera del juicio de pares para publicar; una lenta rotación del personal y el tiempo relativamente largo que toma a los graduados de un primer ciclo formativo encontrar un lugar en la vida adulta de las ocupaciones.

La enseñanza -los que enseñan y los enseñados- no puede mirar solamente hacia el mercado laboral inmediato, sobre todo en tiempos turbulentos. Necesita responder, además, a otras expectativas (no utilitarias) de los estudiantes; al juicio de las comunidades de pares docentes; a las tradiciones reflexivas de las disciplinas y los oficios que cultivan. Y todo esto dentro de las restricciones que le imponen las culturas que convergen en las instituciones formativas.

En breve, los estudiantes que concurren a la universidad realizan allí un proceso vital, un recorrido, una experiencia, una Bildung, y no nada más una carrera, una adquisición de competencias y la obtención de una credencial. Conocer el mundo, habitarlo si se quiere, en sus dimensiones fundamentales -física, biológica, 
de la conciencia, las relaciones sociales, la historia, la apreciación estética- representa hoy una tarea de tal envergadura que aun las mejores mallas curriculares encuentran dificultades para acometerla. Y es dudoso que la tarea pueda alivianarse por el mero expediente de querer destilar esas experiencias de conocimiento bajo la forma de competencias de desempeño aptas para el mundo del trabajo. Dicho en otros términos: la empleabilidad crea un mundo de exigencias que no coincide necesariamente con el mundo del desarrollo personal ni con aquel organizado por las tradiciones disciplinarias.

Todo esto, hay que concederlo, plantea una serie de nuevas interrogantes. Digamos así: las propias preguntas que dirigimos a la universidad en cuanto a la calidad de su vínculo con el mercado laboral puede que hayan empezado a perder pie en la realidad. Y que necesitemos, por tanto, formular otras, distintas, preguntas en relación con los proyectos de vida de los jóvenes, los modos de llevarlos a compartir una experiencia válida del conocimiento, sus itinerarios previsiblemente inciertos en el mercado laboral del futuro o la adecuación o inadecuación de las funciones docentes universitarias respecto de una sociedad de riesgos.

De no hacerlo, se corre el peligro de que las universidades, a propósito de su razonable resistencia a dejarse guiar por unos mercados laborales que se han vuelto demasiado turbulentos como para ofrecer una guía, terminen reforzando los rasgos conservadores y resistentes al cambio que provienen de sus propias tradiciones e intereses corporativos.

En efecto, una cosa es llamar a la reflexión y sujetar a consideración crítica el discurso oficial y empresarial sobre lo que la educación superior debe hacer y no hacer, bajo el argumento de que la economía y el mundo del trabajo exigen o reclaman esto o aquello, y otra, completamente distinta, es usar tales reservas como un subterfugio que serviría a las instituciones para aislarse frente al entorno y volver a erigirse en torres de marfil.

Por el contrario, la universidad contemporánea está forzada -igual como lo estuvo en períodos anteriores del capitalismo- a llevar en cuenta, vitalmente, su entorno, incluidas no sólo las nuevas 
circunstancias del mundo del trabajo sino, igualmente, los efectos que traen consigo los procesos de globalización, la revolución de los medios digitales, la emergencia de sociedades basadas en el uso intensivo del conocimiento (Lundvall, 2007), las transformaciones de la culturas juveniles, la mayor centralidad de los mercados en la coordinación de los sistemas de educación superior, el estrechamiento del rol de los Estados en su sostenimiento y la presión que sobre las instituciones ejerce la universalización de la educación terciaria.

No es que la situación en que operan estas antiguas corporaciones esté cambiando; a fin de cuentas, así ha sido a lo largo de su trayectoria y difusión planetaria. Lo más difícil para ellas, escribe Bauman (1997:24), es cómo abordar "el 'metacambio'; el cambio en las maneras en que la situación está cambiando”.

Esta noción de que algo ha cambiado en las formas de mudar de las cosas es propia, precisamente, de la sensibilidad y el pensamiento posmodernos. Sea que ella aluda al fin de los 'grandes relatos' que habrían acompañado a las revoluciones y el progreso moderno, o a la mutación de las coordenadas espacio-temporales que traen consigo las tecnologías digitales e internet, o a la licuación que hace fluir las estructuras sólidas y las tradiciones creando nuevos riesgos a nuestro alrededor, o a la conformación de un mercado global cuyas transacciones escapan a los Estados nacionales, esta noción de un 'metacambio' describe también el entorno vertiginoso en que hoy se desenvuelven las universidades.

Ellas se ven forzadas ahora a adaptarse al nuevo entorno, ya bien porque los gobiernos las obligan a actuar en mercados administrados o cuasi mercados para procurar su parte de la renta nacional, o bien porque se hallan puestas, directamente, en una 'situación de mercado' según la denomina Weber (1964:62-64), como ocurre en numerosos países en diferentes regiones del mundo (Brunner y Uribe, 2007).

En uno y otro caso, aunque en diferentes grados y de distintas maneras, las instituciones deben competir y diversificar sus fuentes de ingreso; surgen nuevos proveedores (instituciones privadas, universidades corporativas, a distancia, vía internet); los estudiantes pagan aranceles y pasan a ser clientes; los profesores son contratados 
y dejan de ser funcionarios; las funciones institucionales se convierten en desempeños y sujetan a minuciosas mediciones; se enfatiza la eficiencia y el value for money; los modelos de negocio sustituyen en la práctica a los planes estratégicos; la gestión se racionaliza y adopta un estilo empresarial; el gobierno colegiado se transforma en corporativo al independizarse de los académicos e integrarse con representantes de los stakeholders externos; los investigadores son estimulados a patentar y los docentes a vender docencia 'empaquetada' a las empresas; los incentivos vinculados a la productividad académica reemplazan las escalas salariales asociadas al cargo; los currículos son revisados y sancionados en función de su pertinencia laboral y evaluados por agencias externas con relación a su calidad; las culturas distintivas de las instituciones y sus 'tribus académicas' empiezan a ser tratadas como asunto de clima organizacional; las universidades son comparadas por medio de rankings locales y clasificadas geopolíticamente en el plano global (he ahí la realpolitik de los prestigios institucionales); se crea un mercado global para servicios de educación superior y su regulación se resuelve en las rondas del GATS (el Acuerdo General sobre el Comercio de Servicios), no en sedes académicas. En fin, "la universidad ya no es más un lugar tranquilo para enseñar, realizar trabajo académico a un ritmo pausado y contemplar el universo como ocurría en siglos pasados. Ahora es un potente negocio, complejo, demandante y competitivo que requiere inversiones continuas y de gran escala" (Skilbeck, 2001).

Confrontadas con estas nuevas circunstancias-que efectivamente reflejan un 'metacambio'; no sólo nuevas reglas para el mismo juego sino un juego distinto- las universidades y los gobiernos están impedidos, en la práctica, de adoptar como un único parámetro de ajuste de la ES las discontinuas, inestables y confusas señales provenientes del mercado laboral. Tienen ahora frente a sí, si se quiere, múltiples mercados de los cuales deben ocuparse; una diversidad de partes interesadas a las cuales responder. La pertinencia de sus actividades, igual como su calidad, efectividad y eficiencia, se miden de muchas maneras, no necesariamente compatibles entre sí. De allí, entonces, que sus nortes sean más de uno y que por un tiempo habrán de navegar por mares desconocidos. 
Por eso, levantar cartas de navegación, más que armar rankings o establecer benchmarks o imaginar que hay maneras fáciles de transmitir 'buenas prácticas' y 'modelos exitosos', es la tarea más importante. Esta reflexión sugiere algunos derroteros de indagación para acometerla desde ya.

\section{Referencias bibliográficas}

Alonso, L. E., Fernández C. J. y Nyssen J. Mª. (2008) El debate sobre las competencias. Una investigación cualitativa sobre educación superior y mercado de trabajo en España (en prensa).

Bauman, Z. (2007) Los Retos de la Educación en la Modernidad Líquida. Barcelona: Gedisa.

Bauman, Z. (1997) Universities: Old, new and different. En Smith, A. and Webster F. (eds.) The Postmodern University? Contested Visions of Higher Education in Society. Buckingham, UK: SRHE and Open University Press, pp. 17-26.

Becher, T. (2001) Tribus y Territorios Académicos. La Indagación Intelectual y las Culturas de las Disciplinas. Barcelona: Gedisa.

Birnbaum, R. (2001) Management Fads in Higher Education. San Francisco: Jossey-Bass.

Boltanski, L. and Chiapello E. (2005) The New Spirit of Capitalism. London and New York: Verso.

Bourdieu, P. y Passeron J.C. (2003) Los Herederos. Los Estudiantes y la Cultura. Buenos Aires: Siglo Veintiuno Editores Argentina.

Brunner, J.J. y Uribe D. (2007) Mercados Universitarios: el Nuevo Escenario de la Educación Superior. Santiago de Chile: Universidad Diego Portales.

Cranmer, Sue (2006) Enhancing graduate employability: best intentions and mixed outcomes. Studies in Higher Education, 31(2), April 2006, pp. 169-184.

Flores, F. y Gray J. (2000) El Espíritu Emprendedor y la Vida Wired: El Trabajo en el Ocaso de las Carreras, 1-34. Disponible en: http://www.paisdigital. org/node/225

Jongbloed, B., Enders J. and Salerno C. (2008) Higher education and its communities: Interconnections, interdependencies and a research agenda. Higher Education, 56(3), pp. 303-324.

Lundvall, B-A. (2007) Higher Education, Innovation and Economic Development. Paper presented at the World Bank's Regional Bank Conference on 
Development Economics, Beijing, January 16-17, 1-47. Disponible en: http://siteresources.worldbank.org/INTABCDE2007BEI/Resources/ BengtAke.PDF

Núñez, J., Gutiérrez R. (2004) Classism, discrimination and meritocracy in the labor market: The case of Chile. Santiago de Chile: Departamento de Economía, Facultad de Ciencias Económicas y Administrativas, Universidad de Chile, Documento de Trabajo No 208, pp. 1-23. Disponible en: http://repec.org/esLATM04/up.11239.1082127345.pdf

OECD (2008) Tertiary Education for the Knowledge Society (Vols. 1 y 2). Paris: Organization for Economic Co-operation and Development.

Sennett, R. (1998) The Corrosion of Character. The Personal Consequences of Work in the New Capitalism. New York and London: W. W. Norton \& Company.

Skilbeck, M. (2001) The University challenged: A review of international trends and issues with particular relevance to Ireland; Dublin: Higher Education Authority. Versión parcial disponible en: http://iua.webhost.heanet. ie/publications/documents/publications/2001/Report_11.pdf

Teichler, U. (2007) Confirming Conventional Wisdom and Contributing to New Insights: The Results of a Comparative Study on Graduate Employment and Work. The Netherlands: Springer, Higher Education Dynamics Series, Vol. 17.

Teichler, U. (2007a) Does Higher Education Matter? Lessons from a Comparative Graduate Survey. European Journal of Education, 42(1), pp. 11-34.

Weber, M. (1964) Economía y sociedad. Esbozo de sociología comprensiva. México, D. F.: Fondo de Cultura Económica.

Recibido: 10 de octubre de 2008

Aceptado: 20 de octubre de 2008 